\title{
RESEARCH
}

Open Access

\section{Soil transmitted helminth infection in primary school children varies with ecozone in the Ngorongoro Conservation Area, Tanzania}

Manar Eltantawy ${ }^{1}$, Karin Orsel ${ }^{1,2}$, Ashley Schroeder $^{3}$, Domenica Morona $^{4}$, Humphrey D. Mazigo ${ }^{4}$, Susan Kutz ${ }^{3}$, Jennifer Hatfield ${ }^{2}$, Mange Manyama ${ }^{5}$ and Frank van der Meer $^{2,3^{*}}$ (D)

\begin{abstract}
Background: Soil-transmitted helminthiasis is a neglected tropical disease, thriving in environments of poverty and disadvantage. Our objective was to determine the prevalence and intensity of four soil transmitted helminths (STH) among primary school children in the Ngorongoro Conservation Area (NCA), Tanzania.

Methods: A cross-sectional study was performed between May $15^{\text {th }}$ and June $2^{\text {nd }}, 2014$. Six of 20 primary schools were chosen, based on elevation, designated low elevation ecozone (LEE) or high elevation ecozone (HEE). A total of 340 children from standards one to four were recruited. Height and weight of each child was determined and body mass index (BMI) was calculated. Stool samples were analyzed using the Kato-Katz, Wisconsin, and Baermann techniques to detect STH eggs and larvae. An interviewer-administered questionnaire on socio-demographic variables was used to capture information from the school's headmaster and a checklist was used to assess sanitation facilities.

Results: STHs identified included Ascaris (presumably lumbricoides), Trichuris (presumably trichiura), hookworms (presumably Ancylostoma duodenale and/or Necator americanus), and Strongyloides (presumably stercoralis). The overall prevalence of STH infection was $29.0 \%$ in LEE and $34.0 \%$ in HEE. Prevalence was $34.3 \%$ and $28.2 \%$ in males versus females, respectively. Ascaris sp. were only identified in $\mathrm{HEE}$, prevalence of Trichuris sp. and hookworms were significantly higher in HEE compared to LEE, and Strongyloides spp. prevalence was lower in HEE. Intensity of Trichuris sp. was significantly higher in HEE and lower for hookworms. We did not detect a significant relationship between BMI and helminth intensity; however, BMI was lower in lower elevations and in males vs. females. Sanitation practices are taught at the schools, but challenges were identified when implementing. Latrine facilities were available and latrine-cleaning routines were practiced; however, hand washing practices were challenging due to restricted water availability.

(Continued on next page)
\end{abstract}

\footnotetext{
* Correspondence: frank.vandermeer@ucalgary.ca

${ }^{2}$ Department of Community Health Sciences, Cumming School of Medicine,

University of Calgary, Calgary, AB, Canada

${ }^{3}$ Department of Ecosystem and Public Health, Faculty of Veterinary Medicine,

University of Calgary, Calgary, AB, Canada

Full list of author information is available at the end of the article
}

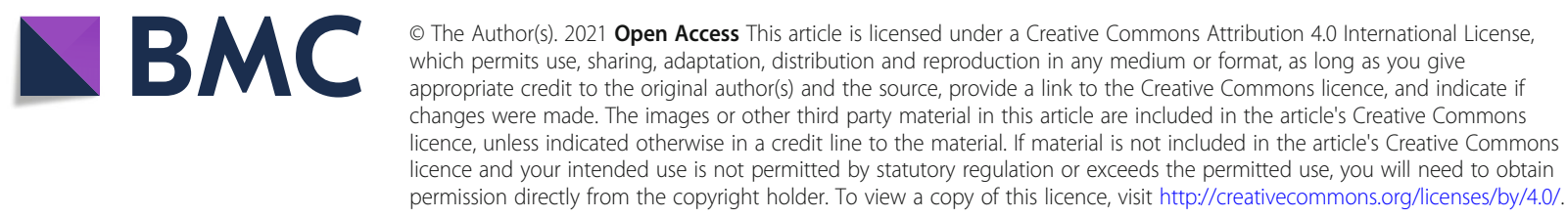


(Continued from previous page)

Conclusions: Significant differences in prevalence in HEE and LEE exist, and STH infections are still very common among school children suggesting that anthelminthic intervention and education may be necessary in this region. Based on this outcome, the study area in the NCA would be classified as a medium risk area, where periodic treatment recommendations should be based on prevalence estimations in the different ecozones.

Trial registration: Ethics approval was obtained from the Catholic University of Health and Allied Sciences (CUHAS; Lake Zone Institutional Review Board MR/53/100/307)); the Conjoint Health Research Ethics Board (CHREB) at the University of Calgary in Canada (Study ID REB14-0127); the National Institute of Medical Research (NIMR) of Tanzania; and the Tanzania Commission for Science and Technology (COSTEC).

Keywords: Soil transmitted helminths, Stool, Elementary schools, Sanitation practices, Diagnostic techniques, Elevation, BMI, Ngorongoro Conservation Area, Tanzania, Strongyloides spp

\section{Background}

Soil-transmitted helminthiasis is recognized as a neglected tropical disease by the World Health Organization (WHO), thriving in environments of poverty and disadvantage [1]. An estimated 2 billion people are parasitized with soil-transmitted helminths (STHs) worldwide, the majority of whom reside in low- and middle-income countries (LMIC) [2]. Clinical signs of severe STH infections include, but are not limited to, abdominal pain, diarrhea, blood and protein loss, and rectal prolapse [3, 4]. Notably, an additional burden can be expected during subclinical infections leading to stunting, reduced body mass index (BMI), and impact on cognitive abilities [5].

Ingestion of infective parasite eggs from the environment are principle routes for transmitting roundworms (e.g., Ascaris lumbricoides) and whipworms (e.g., Trichuris trichiura). Skin penetration of infective larvae is the most common route of transmission for hookworms (e.g., Ancylostoma duodenale and Necator americanus) and threadworms (e.g., Strongyloides stercoralis). These four types of nematodes comprise the majority of STH infections; however, other parasites such as cestodes, trematodes, and protozoa may also be present and cause disease [4]. STH thrive in the warm and damp soils of tropical and subtropical countries, leading to high prevalence of STH in many African countries, especially in communities with challenged socio-economic settings $[6,7]$.

According to the WHO, more than 610 million children of school age are at risk of morbidity due to STHinfections; however, WHO only lists A. lumbricoides, $T$. trichuria, $N$. americanus, and A. duodenale as the core STH species, not including, for example, S. stercoralis and the other helminths [1]. Children are in a period of intense physical growth and rapid metabolism, resulting in high requirements for nutrients and measurable impacts if nutrition is impaired. A potential lack of awareness of personal hygiene and tendency to play in contaminated soil puts children at higher risk of exposure. Therefore, infections can result in growth and cognitive retardation, malnutrition, stunting, and anemia. School attendance rate and school performance (reduced attention) can also be negatively impacted [8].

In Africa, $>89$ million children are estimated to be parasitized with STHs, with many infected with at least two STH species [7, 9, 10]. To allow the easiest approach to treatment of large numbers of school-aged children, schools are often targeted to participate in interventions either to prevent or treat STH parasitism.

Tanzania is classified in the group of so-called LMICs in Eastern Africa and climate, rural lifestyle, and socioeconomic status all contribute to a high risk for school children to contract STH infections [11]. The ministry of health/education in Tanzania provides elementary schools with annual albendazole treatments for children; however, it is unknown if the implementation of this program is equally successful across the country [12]. Information concerning prevalence, intensity, and diversity of STHs infections is scarce for most of Tanzania, especially for the Ngorongoro Conservation Area (NCA). Most studies in Tanzania focus on infections with Plasmodium spp. and Schistosomiasis. In the nearby lake zone, prevalence based on Kato-Katz (KK) testing are $12.6 \%$ for hookworm, 3.2\% A. lumbricoides, and $0.008 \%$ for T. trichiura and, in the Magu district, $0 \%$ for A. lumbricoides and only $0.2 \%$ for $T$. trichiura [13, 14]. Two other studies that focused on coastal regions of Tanzania report prevalence estimations based on $\mathrm{KK}$ of $1.1 \%$ for T. trichuris, $6.1 \%$ for hookworms, and $4.2 \%$ for S. stercoralis [15], and an overall $6.1 \%$ STH prevalence in the Muheza district after $10 \mathrm{y}$ of mass drug treatment implementation [16].

The NCA is a remote rural district of the Arusha region in Northern Tanzania, with 21 wards home to an estimated population of 90,000 inhabitants, mainly of the Maasai tribe. They keep their cattle, goats, and sheep in a pastoralist lifestyle, to ensure optimal utilization of land resources aimed at maximizing production [17]. Maasai communities live in a clanship polygamy, where 
most of the family members live very closely in one big household also called bomas [18].

Due to cultural traditions, e.g., using their hands in eating and walking barefoot, Maasai may be at higher risk of STH exposure [19], as risk is closely associated with contaminated water, poor sanitation, poor hygiene, and poverty [20]. The NCA district has a substantial altitudinal climatic gradient of $600 \mathrm{~m}$ at the caldera's floor in the NCA crater, up to $2200 \mathrm{~m}$ at the crater rim. This results in different ecozones, with low elevation characterized by primarily scattered bushes and short grassy plains and dry hot environments, whereas forests are dominant at high elevations and the climate is cooler with more rain fall and humidity [21]. Environmental conditions can also influence parasite abundance and diversity, with cool moist environments generally being more conducive to parasite survival and transmission than dry hot environments, although some parasite species are better adapted to different extremes in temperatures and/or humidity [22]. The aim of this study was to describe and compare the prevalence, intensity, and polyparasitism of four common STH infections in primary school children in two ecozones of the NCA region.

\section{Materials and methods}

\section{Study area}

This study occurred in the NCA in Northern Tanzania. The area has two rainfall periods, short rains from September to December and long rains from March to May/June. The low elevation ecozone (LEE) is 1000 to $1900 \mathrm{~m}$ above sea level, with an annual rainfall of 500 to $700 \mathrm{~mm}$ and mean monthly temperatures of $17-19{ }^{\circ} \mathrm{C}$. In contrast, the high elevation ecozone (HEE) is characterized by a cool, wet ecozone at $>1950 \mathrm{~m}$ above sea level with an annual rainfall of $800-1200 \mathrm{~mm}$, and lower mean monthly temperatures of $12-14{ }^{\circ} \mathrm{C}$ [23].

\section{Study design and population selection}

The district education officer (DEO), district medical officer (DMO), and NCA dispensary health workers were consulted and asked to prepare a list of all primary schools in the NCA for this study. Six primary schools were chosen and visited between May $15^{\text {th }}$ and June $2^{\text {nd }}$, 2014, based on two criteria. Firstly, no anthelmintic drug treatment was provided through school-based mass medication, to the students in the 6 months prior to the study. Secondly, schools in LEE had to be $\sim 1000$ to $1990 \mathrm{~m}$ above sea level, and HEE at 2000 and $3000 \mathrm{~m}$ above sea level. Sample size estimations to determine the STH prevalence with imperfect tests [24] were combined with a cluster sampling strategy [25], as test objectives are clustered by ecozones. Using this information, the minimum number of schools enrolled was 6 primary schools in the NCA. The sample size for the number of children that were enrolled per school was determined using the methodology recommended by the WHO. This included working with a minimum threshold of 50 school children from each school, regardless of elevation or region [26, 27]. Accordingly, 300 children from standards one to four (ages 8-12 years, with a focus on ages $8-10$ to limit age variation) were recruited based on parental consent and the children's willingness to participate.

We included six primary schools of which three schools were in the LEE, whereas the other three schools were situated in the HEE. Coordinates and elevations for each school were recorded with a hand-held GPS device. The research team visited each school to explain study objectives and procedures with the school headmaster and teachers and to distribute parental consent forms prior to sample collection. Teachers were tasked to explain the study to the parents. The consent form was written in Kiswahili and when necessary, teachers translated it into the local language (e.g., Maa). The sampling visit was scheduled 1 week later.

\section{Field procedures}

Each school was visited by a team consisting of one local elder, a minimum of two local translators of both sexes, and members of the Tanzanian and Canadian university research team. Upon arrival at a school, team members provided communal instructions (in Kiswahili and Maa) regarding the objectives of the study and procedures to be followed. They also provided opportunities for children to ask questions. Thereafter, researchers assembled into three teams, with distinct responsibilities. At the registration station, the children's school, sex, and age were recorded, the latter of which was reported by teachers. At the measurement station, children's height and weight were measured twice and averaged. Stool sample containers were handed out to each child with a paper plate and wooden scoop for self-sample collection. Children were then directed to the latrine to deposit and collect a fresh sample. At the stool collection station (two sub-stations, one for females and one for males), children returned their stool sample to the team, and sanitized their hands. Samples were stored in bags before transportation.

\section{Laboratory procedures}

Stool samples were brought to the Endulen Hospital laboratory the morning of collection. Samples were processed using modified Wisconsin [28] and beaker Baermann techniques [29]. To detect helminth eggs, the Wisconsin technique was modified as follows: feces (5 g) were homogenized in water with a tongue depressor. The stool solution was poured through a single layer 
cheesecloth mesh into a cup; and the filtrate transferred to a $15 \mathrm{~mL}$ test tube with Sheathers solution and centrifuged at $1500 \mathrm{rpm}$ for $5 \mathrm{~min}$ with a glass coverslip on top of the test tube [20]. After centrifugation, the cover slip was lifted straight up and placed onto a microscope slide. Parasite eggs with a specific gravity less than that of the Sheathers solution floated to the top and were collected on the coverslip. This test has a high sensitivity for eggs of three species of STH: Ascaris spp., Trichuris spp., and hookworms [28]. A quantitative Baermann technique was used to detect Strongyloides spp. larvae. We adapted the Baermann method as described by Forrester et al. [29]. Briefly, $5 \mathrm{~g}$ of feces was weighed, placed in a cheesecloth envelope, and suspended below the water surface in a $250 \mathrm{~mL}$ beaker filled with tap water for at least $8 \mathrm{~h}$ (mostly overnight), enabling larvae to move into the water. The fecal packet and supernatant were removed, leaving approximately $15 \mathrm{~mL}$ of sediment which was collected in its entirety and stored in $96 \%$ ethanol (minimum 5:1 ratio) for subsequent microscopic examination at the laboratory of the Catholic University of Health and Allied Sciences (CUHAS) in Mwanza. Parasite eggs and larvae were identified based on morphology [30, 31]. Rhabditiform first stage larvae were identified in the Baermann sediment based on larval morphology and morphometry consistent with that described by Little, 1966 [32].

For quality-control purposes, $~ 10 \%$ of samples for males and females from each school were also processed using the Kato-Katz technique (Vestergaard Frandsen, Lausanne, Switzerland), considered by WHO as a reference test for detecting STH eggs. However, as this test has a reported low sensitivity, it was only included to report prevalence based on this reference test for comparative reasons [33-35]. All samples were processed according to the manufacturer's instructions. A sample was considered positive for helminth infection if at least one helminth egg was present in the Kato-Katz smears or in the Wisconsin analyses, and/or if a larva was present in the Baermann assay. Presences and identification of eggs and/or larvae was determined by AS, who was trained and supported by parasitologists SK/DM and HM (all co-authors).

\section{Headmaster interviews}

The research team conducted interviews on site with the school headmasters to collect information on the student and teacher population, the number of classrooms, water supply, existing food program, the deworming program, as well as sanitation and hygiene education (Appendices 1 and 2).

\section{Latrine inspections}

Latrine facilities were evaluated using an observation checklist that included: types of latrines, cleanliness of the floor, the presence of fecal matter outside the facility, and presence of hand washing facilities (Appendix 2).

\section{Data analysis}

Data were analyzed using the Statistical Package for Social Science (SPSS) software (Version 26.0). Descriptive statistics, such as frequencies, proportions, means, medians, and standard deviations, were computed. As described by [36], prevalence indicates the number of hosts from which at least one parasite egg/larva was isolated divided by the total number of examined hosts and expressed as a percentage; and intensity is the average eggs or larvae per gram of stool tested of a specified parasite in the hosts infected with this parasite [36]. Body mass index was calculated as weight in kilograms divided by the square of height in meters $\left(\mathrm{kg} / \mathrm{m}^{2}\right)$ and interpreted for the age and sex category $[37,38]$. Chisquare $\left(x^{2}\right)$ tests were used to detect statistical differences between categories of explanatory variables and replaced with Fisher' exact tests if cell counts $<5$. A regression model was used to explore associations between sex, ecozone, and BMI of children with helminth intensities, using ecozone as a fixed effect and exploring interactions between ecozone and sex.

\section{Results \\ Study population}

A total of 340 NCA-primary school children, from 6 schools were enrolled in the study. One sample was removed as the sex was not indicated on the form. Table 1 describes the participants demographics.

Briefly, there was a significant difference between the number of children per age group enrolled between the LEE and HEE for age 8 vs. 9,11 and $12(P<0.005)$.

The BMI of participants was within the WHOidentified normal range for age and sex in $89.4 \%$ of the male and $96 \%$ of the female participants, respectively. In a univariate comparison, a significant lower BMI was observed in the LEE, as well as in the males compared to females $(P=0.005$ and $P=0.029$ respectively; Table 2$)$.

\section{Parasitological results: prevalence}

Parasites were identified to the lowest taxonomic classification possible based on morphology. The STH detected included: Ascaris (presumably lumbricoides), Trichuris (presumably trichiura), hookworms (presumably Ancylostoma duodenale or Necator americanus), and Strongyloides (presumably stercoralis) (Table 3). Other parasites typically not considered STH were also documented and quantified and included eggs of a pinworm (Enterobius spp.; Prevalence 2.7\% [0.7-4.7]) unspecified trematode (Prevalence 0.3\% [0.3-1.1]) unspecified cestode (prevalence 6.0\% [3.2-8.9]), and 
Table 1 Demographic status of primary school children in low and high elevation ecozones in the NCA, Tanzania

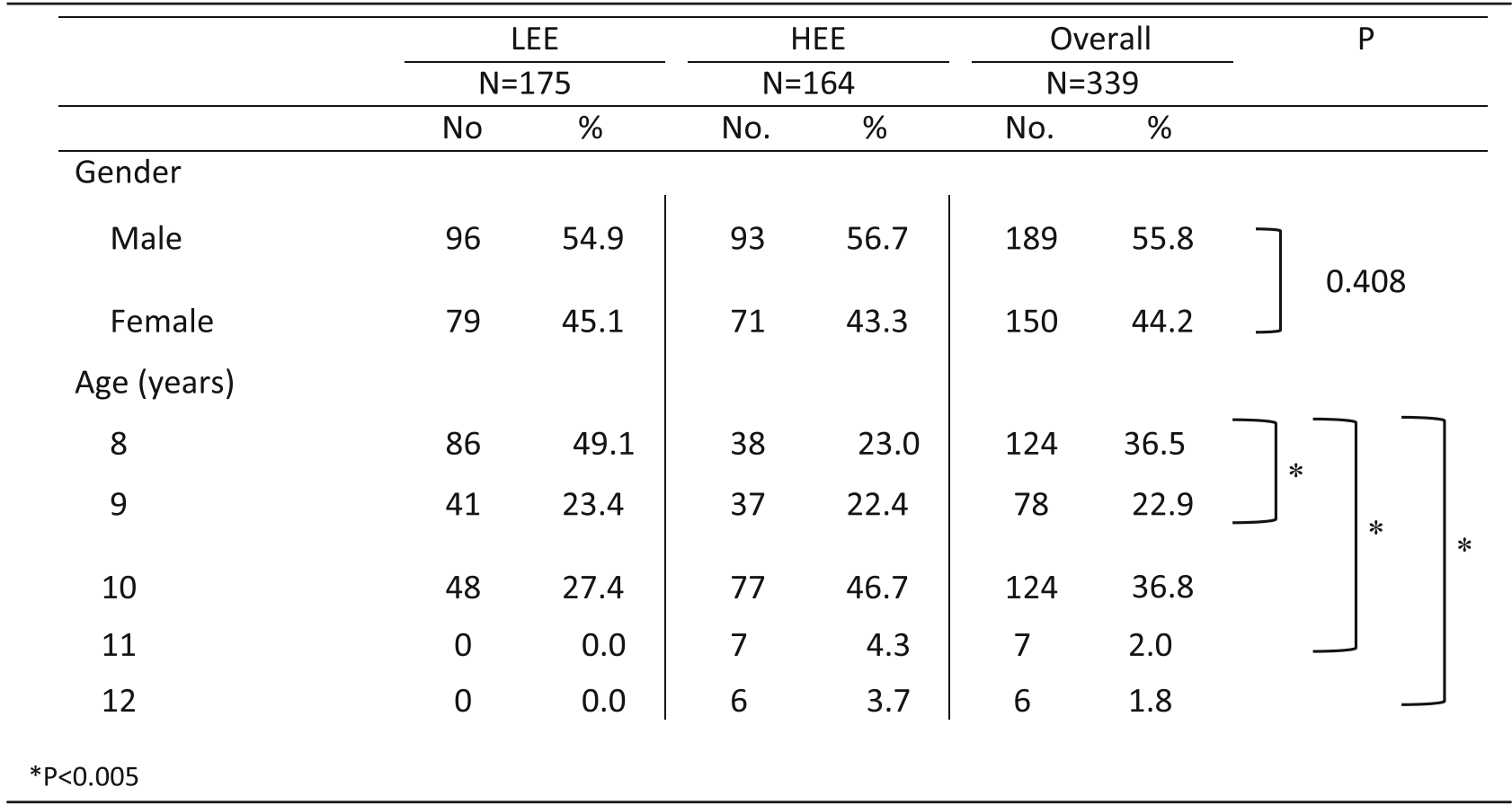

oocysts of Entamoeba spp. (prevalence 2.0\% [0.3-3.8]) and Isospora spp. (Prevalence 0.3\% [0-1.2]).

The overall prevalence of any STH based on the Wisconsin technique was $31.5 \%(95 \% \mathrm{CI}=26-37 \%)$. Prevalence in the LEE was $29.0 \%(95 \% \mathrm{CI}=21-37 \%)$ and in the HEE $34.0 \%$ (95\% CI $=26-42 \% ; P=0.384)$. Overall STH prevalence in males was $34.3 \%(95 \% \mathrm{CI}=27-42 \%)$ versus $28.2 \%(95 \% \mathrm{CI}=20-36 \%)$ in females $(P=0.315)$.

Within the ecozones, there was no significantly difference in prevalence between sexes so the data within an ecozone were merged. The HEE had significantly higher prevalence of Ascaris sp. and Trichuris sp. $(P<0.000$ vs. $P=0.010$ respectively, Table 3$)$, compared to the LEE.

Table 2 BMI classification by sex presented per ecozone

\begin{tabular}{|c|c|c|c|c|c|c|}
\hline & \multirow{2}{*}{$\begin{array}{l}\text { LEE }^{\mathrm{a}} \\
N=175 \\
\text { No }\end{array}$} & \multicolumn{3}{|c|}{$\begin{array}{l}\text { HEE } \\
N=164\end{array}$} & \multicolumn{2}{|c|}{$\begin{array}{l}\text { Overall } \\
N=339\end{array}$} \\
\hline & & $\%$ & No & $\%$ & No & $\%$ \\
\hline$\overline{M a l e^{b}}$ & $N=96$ & & \multicolumn{2}{|c|}{$N=93$} & \multicolumn{2}{|c|}{$N=189$} \\
\hline Severe thinness ${ }^{c}$ & 1 & 1 & 0 & 0 & 1 & 0.5 \\
\hline Thinness & 9 & 9.4 & 10 & 10.8 & 19 & 10.1 \\
\hline Normal & 86 & 89.6 & 83 & 89.2 & 169 & 89.4 \\
\hline Female & \multicolumn{2}{|l|}{$N=79$} & \multicolumn{2}{|c|}{$N=71$} & \multicolumn{2}{|c|}{$N=150$} \\
\hline Severe thinness & 0 & 0 & 0 & 0 & 0 & 0 \\
\hline Thinness & 6 & 7.6 & 0 & 0 & 6 & 4.0 \\
\hline Normal & 73 & 92.4 & 71 & 100 & 144 & 96.0 \\
\hline
\end{tabular}

${ }^{\mathrm{a}}$ Fisher exact $P$ value between ecozones $P=0.005$

${ }^{\mathrm{b}}$ Fisher exact $P$ value between sex $P=0.029$

'Based on WHO definitions [37]
Based on a subset of samples $(N=62)$ that were processed using both the Wisconsin and Kato-Katz techniques, prevalence was significantly lower for the KK (32.2\%; 95\% CI $=20-44 \%$ ) compared to the Wisconsin (43.5\%; 95\% CI $=30.4-56.7 \%)$ technique $(P=0.000)$. The sensitivity of the KK technique was $63 \%$ and specificity was $91 \%$ relative to the Wisconsin technique (Tables 4 and 5).

\section{Parasitological results: intensity}

Intensity, as expressed by eggs per gram (EPG) and larvae per gram (LPG), is summarized in Table 6. Additional observations were low intensities for Enterobius spp. in all sex and ecozone groups $(n=8)$, and one female in HEE with 1.0 EPG for unspecified trematode eggs. The univariate linear regression identified no significant correlation between the four STH intensities and either BMI classification or age (y). Ascaris sp. was only observed in the HEE with a significantly higher intensity in male vs female $(P=0.03)$. However, for Trichuris, a significant difference was observed between males in both ecozones $(P=0.03)$ and females in both ecozones $(P=0.01)$. Overall, the intensity of Trichuris sp. and hookworms was significantly different in HEE vs. LEE when combined for both sexes $(P=0.001$ vs. $P=$ 0.05 respectively; Table 6 ).

Finally, co-infections were compared between the sexes in the two ecozones, and no significant difference were found (Table 7). 
Table 3 Summary of prevalence (95\% confidence interval) of four soil transmitted helminths with respect to ecozone and sex of children in the Ngorongoro Conservation Area

\begin{tabular}{lllll}
\hline & Ascaris sp. & Trichuris sp. & Hookworms & Strongyloides spp. \\
\hline $\begin{array}{l}\text { Overall prevalence } \\
(95 \% \mathrm{Cl})\end{array}$ & $4.0(1.6-6.4)$ & $8.4(5.0-11.7)$ & $13.0(9.1-17.1)$ & $27.4(21.4-33.4)$ \\
Overall prevalence HEE $(95 \% \mathrm{Cl})$ & $7.8^{\mathrm{a}}(3.3-12.4)$ & $12.4^{\mathrm{a}}(6.9-18.0)$ & $14.4^{\mathrm{a}}(8.5-20.3)$ & $21.7^{\mathrm{a}}(12.9-30.4)$ \\
HEE Male $(95 \% \mathrm{Cl})$ & $5.8(0.3-11.2)$ & $14.9(6.9-23.0)$ & $17.2(8.7-25.8)$ & $29.0(16.1-42.0)$ \\
HEE female $(95 \% \mathrm{Cl})$ & $10.8(2.5-19.1)$ & $9.2(1.4-17.0)$ & $10.8(2.5-19.0)$ & $11.9(0.9-22.9)$ \\
Overall prevalence LEE $(95 \% \mathrm{Cl})$ & $0^{\mathrm{b}}$ & $\left.4.0^{\mathrm{b}}(0.6-7.7)\right)$ & $11.7^{\mathrm{a}}(6.1-17.3)$ & $31.6^{\mathrm{a}}(23.3-40.0)$ \\
LEE male $(95 \% \mathrm{Cl})$ & 0 & $3.8(0-8.7)$ & $17.7(8.7-26.8)$ & $27.5(16.2-38.8)$ \\
LEE female $(95 \% \mathrm{Cl})$ & 0 & $4.5(0-10.2)$ & $4.5(0-10.2)$ & $35.9(23.4-48.5)$ \\
\hline
\end{tabular}

HEE is high elevation ecozone; LEE is low elevation ecozone. Different superscript $\left({ }^{\mathrm{a}, \mathrm{b}}\right)$ within row indicates significant differences $P<0.05$

\section{School survey}

Water accessibility was evaluated by asking each headmaster to identify the main source of water for their school during rainy and dry seasons. In the LEE, all three schools collected rainwater during the rainy season; two schools also sent children to retrieve water from the river, whereas one pumped water from the river (when diesel was available to operate the pump). None of the schools tested water quality or treated water. In the HEE, two of the three schools got their water from the river and the other got it from water sources within the Ngorongoro crater. For all three HEE schools, water was transported by pipes, but only the school that got water from the crater treated the water with chlorine.

At all six schools, latrine facilities were available with cleanable cement floors and roofing. Although latrinecleaning routines were practiced, in three out of six facilities fecal contamination of the environment was observed. Hand-washing facilities were only available close to the latrine in one school in LEE, using a small plastic bucket filled with water. Another school had a washing facility that was broken at the time of the study visit. Soap was only available in one school. In the HEE, one school had a tippy tap (large plastic containers hanging from a tree) and the other had a water bucket.

An antiparasitic program (albendazole) was rolled out in 2012 ( 2 years prior to the study) at two LEE schools and at one HEE school. For the three other schools, data

Table 4 Agreement between Wisconsin and Kato-Katz techniques for soil transmitted helminth egg detection combined

\begin{tabular}{lllll}
\hline & & Wisconsin & \\
\cline { 3 - 5 } & & Positive $(\mathbf{N})$ & Negative $(\mathbf{N})$ & Total $(\mathbf{N})$ \\
\hline Kato-Katz & Positive $(\mathrm{N})$ & 17 & 3 & 20 \\
& Negative $(\mathrm{N})$ & 10 & 32 & 42 \\
& Total $(\mathrm{N})$ & 27 & 35 & 62 \\
\hline
\end{tabular}

on deworming were not available. Sanitation and hygiene education were confirmed to be included in science classes at LEE schools.

\section{Checklist results}

Two schools had "improved traditional pit latrine" and four had a "VIP latrine," where VIP latrines are defined as cement floor supported by reinforced iron bar or wood, wood and mud plastered or brick or block wall, corrugated iron roof or thatch roof cover, ventilated through installed vent pipes (Appendix 2). No cleaning material was visibly available. Fecal material was noticed outside the pit, on the floor, or on the walls at four schools. Females' facilities appeared to be cleaner than those for males. Cleanliness level varied among schools; with some in need of sanitizing, whereas others appeared to have been recently cleaned.

\section{Discussion}

This cross-sectional study generated estimates on prevalence and intensity of four STHs among primary school children in six schools in the NCA. School-based antiparasitic programs had not been implemented within at least 6 months in any of these schools, ensuring that recent treatments would not affect the results. STH prevalence estimations for a subset of samples analyzed using the Kato-Katz, the WHO recommended diagnostic test, was $32.3 \%$. Based on this, the study area in the NCA would be classified as a medium risk area, where

Table 5 Prevalence (95\% confidence interval) comparison of three soil transmitted helminths detected $(N=65)$ with Wisconsin and Kato-Katz in the Ngorongoro Conservation Area

\begin{tabular}{lccc}
\hline & Ascaris sp. & Trichuris sp. & Hookworms \\
\hline Overall prevalence & & & \\
Wisconsin $(95 \% \mathrm{Cl})$ & $3.2(0-8.4)$ & $11.3(2.6-20.0)$ & $19.4(8.7-30.0)$ \\
Prevalence & & & \\
Kato Katz $(95 \% \mathrm{Cl})$ & $3.1(0-8.0)$ & $7.7(0.4-14.9)$ & $3.1(0-8.0)$ \\
\hline
\end{tabular}


Table 6 Intensity (median EPG/LPG; min-max) of four soil transmitted helminths with respect to elevation and sex of children in the Ngorongoro Conservation Area

\begin{tabular}{lllll}
\hline & Ascaris sp. & Trichuris sp. & Hookworms & Strongyloides spp. \\
\hline Overall intensity (Min-Max) & $165.3(0.6-8653.9)$ & $5.1(0.2-61.8)$ & $0.6(0.2-10.2)$ & $0.2(0.2-4.7)$ \\
Infected children & $N=12$ & $N=19$ & $N=22$ & $N=21$ \\
Intensity HEE (Min-Max) & $165.3(0.6-8653.9)$ & $6.4(0.4-61.8)$ & $0.4(0.2-9.8)$ & $0.2(0.2-2.2)$ \\
HEE ${ }^{*}$ male (Min-Max) & $242.7(188.9-8653.9)$ & $5.5(0.4-61.8)$ & $0.4(0.2-9.8)$ & $0.4(0.2-2.2)$ \\
HEE female (Min-Max) & $80.8(0.6-231.4)$ & $7.0(2.3-34.3)$ & $0.4(0.2-3.9)$ & $0.2(0.2-0.2)$ \\
Infected children & $N=0$ & $N=6$ & $N=17$ & $N=42$ \\
Intensity LEE (Min-Max) & & $0.7(0.2-5.1)$ & $0.8(0.3-10.2)$ & $0.2(0.2-4.7)$ \\
LEE male (Min-Max) & 0 & $0.4(0.2-5.1)$ & $1.0(0.4-8.2)$ & $0.2(0.2-4.7)$ \\
LEE female (Min-Max) & 0 & $0.8(0.6-1.7)$ & $0.8(0.4-10.2)$ & $0.2(0.2-2.2)$ \\
\hline
\end{tabular}

HEE is high elevation ecozone; $L E E$ is low elevation ecozone; $E P G$ Eggs per gram; $L P G$ Larvae per gram

periodic treatment recommendations should be based on diagnostic testing in the different ecozones. When prevalence estimations are $>50 \%$, WHO recommends a bi-annual treatment protocol [9]. With the more sensitive technique based on the Wisconsin protocol, our prevalence estimation in the same subset was $43.5 \%$, and the overall prevalence estimation based on all available samples was $31.5 \%$, neither exceeding the prevalence cut-off for high-treatment frequencies. Kato-Katz is the most frequently used technique in the field; however, other studies have identified the challenges with limited sensitivities of KK $[35,39]$ and have compared KK to FLOTAC or PCR technologies. Knopp et al. [35] reported the FLOTAC being more sensitive to detect hookworms and S. stercoralis compared to KK. They also found KK to be equally sensitive as PCR for these same parasites, whereas Verweij et al. [39], reported a higher sensitivity using PCR. Kato-Katz is not recommended for Strongyloides spp. and various versions of the Baermann technique have been used to improve its sensitivity [35]. In our study, using an adjusted Baermann technique, the overall prevalence of Strongyloides spp. was $27.4 \%$, higher than reported in studies in Angola (11.3\%) and on Zanzibar (10.8\%) [40, 41]; both studies of which also used a version of the Baermann technique. While these differences may be in part be linked to differences in the climate, environment, and

Table 7 Co-infection with soil-transmitted helminths (STH) of children in the Ngorongoro Conservation Area with respect to elevation and sex

\begin{tabular}{llllll}
\hline & LEE male & LEE female & HEE $^{*}$ male & HEE female & Total \\
\hline No STH & 53 & 50 & 56 & 44 & 203 \\
One STH & 23 & 14 & 23 & 16 & 76 \\
Two STH & 3 & 2 & 7 & 5 & 17 \\
Three STH & 0 & 0 & 1 & 0 & 1 \\
\hline
\end{tabular}

HEE is high elevation ecozone; LEE is low elevation ecozone lifestyle (pastoralist in the current study), the different methods for fecal analysis likely play an important role as well. Both Knopp and de Alegria's studies used a modified Baermann funnel technique which is known to be less sensitive than the beaker-Baermann technique used in this study [29]. Additionally, in Knopp's study, the Baermann funnels were set up for only $2 \mathrm{~h}$ compared to at least $8 \mathrm{~h}$ in the current study; restricting the time available for larvae to migrate out of feces and end up in the sediment.

The high prevalence of Strongyloides spp. may be attributed to the plasticity in its lifecycle that may allow it to persist under adverse conditions. The LEE had the highest prevalence estimations of Strongyloides spp., similar to small-scale studies in rural Côte d'Ivoire also at lower elevation (e.g., Lake Taboo at $400 \mathrm{~m}$ ) [42], emphasizing the potential role of the local climatological differences.

Amor et al. also emphasized the Baermann or combined diagnostics for Strongloides detection, and also stated that albendazole, which is the common anthelminthic used in school programs in Tanzania, is not the treatment of choice for Strongyloides spp. [43]. This may also contribute to the higher prevalence of this STH observed in this study, as albendazole is the anti-parasitic drug of choice in the school programs [12]. Finally, the WHO does not include Strongyloides spp. infections in the neglected tropical diseases, and might therefore not get the attention this $\mathrm{STH}$ deserves in prevention and control (ref 1; new WHO included).

Despite the use of the more sensitive Wisconsin technique, we detected a low prevalence of $A$. lumbricoides of $4.0 \%$, and only detected it in the HEE. These results are comparable to data from Angola in children (5-14 years) where also a low prevalence of $1.3 \%$ was reported [41], but lower than those in southwest Ethiopia where prevalence was 39.5\% [44] and in northwest Ethiopia where prevalence was $39.8 \%$ [45]. The reasons for the 
low prevalence in our study, and the absence from the LEE are unknown, but may reflect a successful mass treatment program. Although our data did not have sufficient spread in age categories, age susceptibilities have been reported in the past $[46,47]$.

Our main interest in comparing ecozones was motivated from the expected survival of STH eggs and larvae in the more favorable climate of the cooler and more humid HEE. Climate and seasonality can have considerable impacts on transmission dynamics, with significant interannual and within region fluctuations occurring depending on precipitation and temperature $[48,49]$. Understanding these ecological drivers and dynamic patterns is needed in order to guide intervention strategies. Summarizing, indeed the overall prevalence in the HEE was higher with $34.0 \%$, and significantly higher prevalence of Ascaris sp. and Trichuris sp. compared to LEE.

Finally, when reflecting on the potential difference of STH infections in sex, behaviors based on roles in the community should be taken into account. Males had a significantly higher prevalence of Trichuris sp. compared to females in the present study. In other settings, males were also identified at higher risk of infection compared to females, and this may be driven by different behaviors associated with their different roles in society (herding vs doing chores near the home) [50-52].

In our study, we observed evidence of possible low hygiene and sanitation in the schools. For instance, hand washing facilities were present in three schools only, and no soap or ash was available for hand washing at any of the six schools. Another study in the same area in the NCA, including both ecozones, identified low hygiene standards in the same communities [18]; however, the NCA would all classify as rural setting and therefore not reflecting hygiene standards more common in urban settings. Substandard hygiene associated with the latrine facilities in schools may lead to fecal contamination of hands with helminth eggs, facilitating the spread of parasitic infections. The survey of headmasters and school inspections revealed that, despite implementation of health and sanitation in the curriculum, many schools struggled to keep infrastructure and basic hygiene facilities functional and available to children as well as present these components in of the curriculum to the students. Support for schools that increases hygiene status is likely to reduce the probability of STH infections in children. In addition, other local and cultural factors, such as eating with fingers as opposed to utensils, and/ or behavioral factors, such as walking barefoot and hand hygiene, were not considered in this study and can impact transmission.

As with many field studies, this study has limitations. Only six of 20 public schools were enrolled, and no private schools were included. Only children attending schools participated in the study resulting in a biased sample that may not be representative of all children in this age range in this part of the NCA. Childrens' ages were self-reported by teachers who based their reporting on incomplete school records. Also, we limited the age range to $8-12$, thus results will not be representative of younger or older children. Finally, the study might lack power to find potentially existing differences, as some sex and age groups have lower numbers of participants or observed prevalence and intensities were low. Additionally, the study occurred at a single point in time (following the "short" rains) and did not span different seasons. Given the seasonality of most parasites, our study may have over, or underestimated, depending on the parasite species, the annual parasite burden in this region.

We did not inquire about clinical signs consistent with parasitism that children may have experienced. This additional information could inform the knowledge of STH infection symptoms as well as the interference with other common diseases within the list of neglected tropical diseases. Further surveys could include questions on education of parents and older siblings, health, and sanitation routines outside of school (e.g., clipping of fingernails, the presence of livestock on the home property, handwashing, latrine facilities, and wearing shoes).

\section{Conclusions}

In conclusion, significant differences in prevalence in high and low ecozones exist, and STH infections are still very common among school children suggesting that anthelminthic intervention and education may be necessary in this region.

\section{Appendix 1}

Primary School Interview Form

Interviewer ID:

Date of Interview:

Total number of child forms collected From ID\# to ID\#

\section{General Information}

Name of District: Name of School:

Name of School Headmaster:

Name of Deputy School Director: Telephone Number of Headmaster:

Distance from town/village $\mathrm{km}$

Distance to closest dispensary/hospital km GPS coordinates

2. Student and Teacher Population 


\begin{tabular}{lll}
\hline & $\begin{array}{c}\text { Total } \\
\text { No. of } \\
\text { Males }\end{array}$ & $\begin{array}{l}\text { No. of } \\
\text { Females }\end{array}$ \\
\hline Students & & \\
Teachers & & \\
Performance on St. 7 exam & & \\
$\%$ transitioning to secondary & & \\
school & & \\
\hline
\end{tabular}

\section{Classrooms}

Total number of classrooms

Average number of pupils per classroom

4. Water Supply

a) Please describe the water supply at the school. What is the source? How far away does it come from? How is it stored?

b) Is the water tested, or treated before use? If yes, how?

5. Hand Washing Facilities

a) Does the school have hand washing facilities? If so, what kind? (Sink and faucet, bucket, basin, tippy tap)

b) Is their soap/ash available to wash hands?

c) When do students wash hands?

6. Latrine Facilities

a) Are there latrines at the school? If no, where do students and teachers go to urinate/defecate?

b) Is there a latrine-cleaning program? If yes, who cleans the latrines? How often?

\section{School Feeding Program}

a) Please describe the current school feeding program (who pays for it, what food is provided, which meals)

b) Please describe the school feeding program in the past (who paid for it, what food was provided, which meals, if it was ever interrupted)

c) Please describe any future plans or goals for the school feeding program.

d) Does the school feeding program need improvement? If so, how could it improve?

8. School Deworming Program

a) Is there a deworming program in place at this school? If yes, who pays for it and who administers the drugs to students?

b) What drugs are given to children? How often? When were drugs last administered at this school?

c) Do you know if children that are not in school get deworming medications? If so, how?

d) Do you feel the deworming program is effective? If not, how could it be improved?

9. School Hygiene Lessons

a) Is hygiene education part of the school curriculum? If yes, which standards receive lessons on hygiene? Is hand washing taught in the lessons?

b) Are staff trained in providing hygiene education?

c) Are there supporting teaching materials available?

d) Are there any extracurricular activities or school clubs that include hygiene activities?

e) Are there any posters, other IEC materials with hygiene messages on walls?

\section{Appendix 2}

Primary School Observation Checklist

1. Latrine Facilities

1 What types of latrines are the school (mark one):o Noneo Traditional pit latrine (dirt floor supported by logs of wood, wood walls with mud plastered, corrugated iron roof or thatcho Improved traditional pit latrine (washable cement floor, supported by logs or reinforced, wood and mud walls, corrugated iron or thatch roof)o VIP latrine 


\section{Appendix 2 (Continued)}

(cement floor supported by a reinforced iron bar or wood, wood and mud plastered or brick or block wall, corrugated iron roof or thatch roof cover, ventilated through installed vent pipes)

3 Are there separate facilities for boys and girls? Yes No

4 Number of squat holes available for boys

5 Number of squat holes available for girls:

6 Do boys have urinals?

7 Do facilities have doors or curtains for privacy for Yes NoNo boys? Do facilities have doors or curtains for privacy Yes for girls?

8 Can facilities be locked for safety and privacy? Yes No

9 Is there wiping material available in the facilities? Yes No

\section{Latrine Cleanliness}

1 Is there fecal material deposited outside the pit or on the floor?

2 Anal cleaning material or toilet paper on floor?

3 Additional comments/observations

\section{Hand Washing Facilities}

\begin{tabular}{lll}
\hline 1 & Are hand washing facilities near the latrines? & Yes No \\
2 & Is there water in the containers? & Yes No \\
3 & Is there soap, ash, or other near the wash stand? & Yes No \\
4 & Is there any reminder for hand washing near latrine? & Yes No
\end{tabular}

\section{School compound Comments/observation}

\section{Abbreviations}

BMI: Body mass index; CHREB: Conjoint health research ethics board; Cl: Confidence interval; COSTEC: Tanzania commission for science and technology; CUHAS: Catholic university of health and allied sciences; DEO: District education officer; DMO: District medical officer; EPG: Eggs per gram; HEE: High elevation ecozone; KK: Kato-katz; LEE: Low elevation ecozone; LMIC: Low- and middle-income countries; LPG: Larvae per gram; Max: Maximum; Min: Minimum; NCA: Ngorongoro conservation area; NIMR: National institute of medical research; spp.: Species; SPSS: Statistical package for social science; STH: Soil transmitted helminths; WHO: World health Organization

\section{Acknowledgements}

The authors thank the district educational officer, district medical officer, headmasters, schoolteachers, school children, and their parents for their wholehearted cooperation throughout the study. Special thanks to Dr. Warren Wilson who trained researchers in body measurements and to James
Wang for laboratory support. This study could not have happened without the dedication of local partners, in particular Saningo Godwin, Kimani, Jackson, Laizer, Kishimbashi, all translators in the field, the staff of University of Calgary and the parasitology lab at the Catholic University of Health and Allied Science (CUHAS), as well as Endulen hospital in the NCA. Also, we like to thank all elementary school children participating in this field study to assist with data collection and processing.

\section{Authors' contributions}

ME wrote the manuscript and analyzed the data. $\mathrm{KO}$ wrote the manuscript, analyzed the data, participated in the field data collection. AS Field data collection, sample analysis. DM analyzed the data, sample analysis. HM wrote the manuscript, analyzed the data, sample analysis. SK wrote the manuscript, analyzed the data, participated in the field data collection. JH wrote the manuscript, coordinated field activities, performed interviews. MM wrote the manuscript, coordinated field activities, performed interviews. FM wrote the manuscript, analyzed the data, participated in the field data collection, overall coordination. All authors read and approved the final manuscript.

\section{Funding}

Financial support was received from the Departments of Community Health Sciences, Production Animal Health and Ecosystem and Public Health of the Faculty of Veterinary Medicine and the Cumming School of Medicine, University of Calgary, Calgary, AB, Canada.

\section{Availability of data and materials}

The datasets generated and/or analyzed during the current study are not publicly available due to privacy reasons but are available on basis of anonymity from the corresponding author on reasonable request. There are no materials available.

\section{Declarations}

Ethics approval and consent to participate

Ethics approval was obtained from the Catholic University of Health and Allied Sciences (CUHAS; Lake Zone Institutional Review Board MR/53/100/ 307)); the Conjoint Health Research Ethics Board (CHREB) at the University of Calgary in Canada (Study ID REB14-0127); the National Institute of Medical Research (NIMR) of Tanzania; and the Tanzania Commission for Science and Technology (COSTEC). Support letters were obtained from the DMO and DEO. School teachers informed the parents and requested written consent from a parent of each student before data collection started. After the study, in November 2014, the DMO, DEO, and teachers were informed of overall outcomes of the study, e.g. prevalence of helminth infections in the children at each school. Individual results were communicated by a health expert of the research team to the local authorities only if DMO provided anthelmintic treatment (albendazole or mebendazole) was not deemed sufficient to ensure the health of the child.

\section{Consent for publication}

Not applicable.

\section{Competing interests}

The authors declare that they have no competing interests.

\section{Author details}

1Department. of Production Animal Health, Faculty of Veterinary Medicine, University of Calgary, Calgary, AB, Canada. ${ }^{2}$ Department of Community Health Sciences, Cumming School of Medicine, University of Calgary, Calgary, $A B$, Canada. ${ }^{3}$ Department of Ecosystem and Public Health, Faculty of Veterinary Medicine, University of Calgary, Calgary, AB, Canada. ${ }^{4}$ Department of Parasitology, Catholic University of Health and Allied Science, Mwanza, Tanzania. ${ }^{5}$ Division of Medical Education, Weill Cornell Medicine - Qatar, Doha, Qatar.

Received: 22 September 2020 Accepted: 22 February 2021 Published online: 10 March 2021

\section{References}

1. World Health Organization. Ending the neglect to attain the Sustainable Development Goals: A road map for neglected tropical diseases 2021-2030. 
[Internet]. 2020 [cited 2020 Dec 19]. Available from: https://www.who.int/ neglected_diseases/resources/who-ucn-ntd-2020.01/en/

2. Hotez PJ, Kamath A. Neglected tropical diseases in sub-saharan Africa: review of their prevalence, distribution, and disease burden. PLoS Negl Trop Dis. 2009;3(8):e412.

3. Centers for Disease Control and Prevention. Parasites_-soil-transmitted helminths [Internet]. [cited 2020 Dec 19]. Available from: https://www.cdc. gov/parasites/sth/

4. Bethony J, Brooker S, Albonico M, Geiger SM, Loukas A, Diemert D, et al. Soil-transmitted helminth infections: ascariasis, trichuriasis, and hookworm. Lancet. 2006;367(9521):1521-32.

5. Garzon M, Pereira-da-Silva L, Seixas J, Papoila AL, Alves M. Subclinical enteric parasitic infections and growth faltering in infants in Sao Tome, Africa: a birth cohort study. Int J Env Res Public Health. 2018;15(4):688.

6. Weaver HJ, Hawdon JM, Hoberg EP. Soil-transmitted helminthiases: implications of climate change and human behavior. Trends Parasitol. 2010;26(12):574-81.

7. Karagiannis-Voules DA, Biedermann P, Ekpo UF, Garba A, Langer E, Mathieu E, et al. Spatial and temporal distribution of soil-transmitted helminth infection in sub-Saharan Africa: a systematic review and geostatistical metaanalysis. Lancet Infect Dis. 2015;15(1):74-84.

8. Freudenthal S, Ahlberg BM, Mtweve S, Nyindo P, Poggensee G, Krantz I. School-based prevention of schistosomiasis: Initiating a participatory action research project in northern Tanzania. Acta Trop. 2006;100(1-2):79-87.

9. World Health Organization, Department of control of neglected tropical diseases. Helminth control in school age children; a guide for managers of control programmes [Internet]. Second edition. 2011 [cited 2020 Dec 19]. Available from: https://www.who.int/neglected_diseases/resources/9789241 548267/en/

10. Lai YS, Biedermann P, Ekpo UF, Garba A, Mathieu E, Midzi N, et al. Spatial distribution of schistosomiasis and treatment needs in sub-Saharan Africa: a systematic review and geostatistical analysis. Lancet Infect Dis. 2015;15(8): 927-40.

11. Steinmann P, Keiser J, Bos R, Tanner M, Utzinger J. Schistosomiasis and water resources development: systematic review, meta-analysis, and estimates of people at risk. Lancet Infect Dis. 2006;6(7):411-25.

12. The United Republic of Tanzania. The Ministry of Health, Community Development, Gender E and C. Guidelines for Fronline Health Workers. Supply Chain management of medicines for mass drug administration campaigns for neglected tropical diseases in Tanzania mainland [Internet]. 2016 [cited 2020 Dec 19]. Available from: https://adphealth.org/upload/ resource/NTD-FLHW.pdf

13. Kinung'hi SM, Magnussen P, Kaatano GM, Kishamawe C, Vennervald BJ. Malaria and helminth co-infections in school and preschool children: a cross-sectional study in Magu district, North-Western Tanzania. PLoS One. 2014;9(1):e86510.

14. Siza JE, Kaatano GM, Chai JY, Eom KS, Rim HJ, Yong TS, et al. Prevalence of schistosomes and soil-transmitted helminths among schoolchildren in lake Victoria basin, Tarzania. Korean J Parasitol. 2015;53(5):515-24.

15. Salim N, Knopp S, Lweno O, Abdul U, Mohamed A, Schindler T, et al. Distribution and risk factors for plasmodium and helminth co-infections: a cross-sectional survey among children in Bagamoyo District, Coastal Region of Tanzania. PLoS Negl Trop Dis. 2015;9(4):e0003660.

16. Ngasala B, Matata F, Mwaiswelo R, Mmbando BP. Anemia among schoolchildren with malaria and soil-transmitted helminth coinfections after repeated rounds of mass drug administration in Muheza district, Tanzania. Am J Trop Med Hyg. 2019;101(5):1148-55.

17. Boone RB, Galvin KA, Thornton PK, Swift DM, Coughenour MB. Cultivation and conservation in Ngorongoro Conservation Area, Tanzania. Hum Ecol. 2006:34(6):809-28.

18. Nyanza EC, Jahanpour O, Hatfield J, Van Der Meer F, Allen-Scott L, Orsel K, et al. Access and utilization of water and sanitation facilities and their determinants among pastoralists in the rural areas of northern Tanzania. Tanzan J Health Res. 2018;20(1):1-10.

19. Barnes AN, Davaasuren A, Baasandagva U, Gray GC. A systematic review of zoonotic enteric parasitic diseases among nomadic and pastoral people. PLoS One. 2017;12(11):e0188809.

20. Garcia LS. Diagnostic Medical Parasitology. Fifth ed. Washington, D.C.: ASM Press; 2007. p. 1202.

21. Homewood KM, Rodgers WA. Maasailand Ecology; Pastoralist development and wildlife concervation in Ngorongoro. Tanzania: Cambridge University Press; 2004
22. Mas-Coma S, Valero MA, Bargues MD. Effects of climate change on animal and zoonotic helminthiases. Rev Sci Tech. 2008;27(2):443-57.

23. Fick SE, Hijmans RJ. WorlClim Version2: Average temperature. 2016. [cited 2020 Dec 19]. Available from: http://worldclim.org/.

24. Thrusfield M, Christley R. Veterinary Epidemiology. Fourth ed. Hoboken: Wiley Blackwell; 2018.

25. Fosgate GT. Practical sample size calculations for surveillance and diagnostic investigations. J Vet Diagn Investig. 2009;21:3-14.

26. World Health Organization. Action against worms N04 [Internet]. Allen H, editor. 2004 [cited 2020 Dec 19]. Available from: https://www.who.int/ intestinal_worms/resources/AAW_4_en/en/

27. World Health Organization. Preventive chemotherapy in human helminthiasis; coordinated use of anthelmintic drugs in control interventions; a manual for health professionals and prgramme managers [Internet]. Engels D, editor. 2006 [cited 2020 Dec 19]. Available from: https:// www.who.int/neglected_diseases/resources/9241547103/en/

28. Egwang TG, Slocombe JO. Evaluation of the Cornell-Wisconsin centrifugal flotation technique for recovering trichostrongylid eggs from bovine feces. Can J Comp Med. 1982;46(2):133-7.

29. Forrester SG, Lankester MW. Extracting Protostrongylus spp. larvae from bighorn sheep feces. J Wildl Dis. 1997;33(4):868-72.

30. Garcia LS, Arrowood M, Kokoskin E, Paltridge GP, Pillai DR, Procop GW, et al. Laboratory Diagnosis of Parasites from the Gastrointestinal Tract. Clin Microbiol Rev. 2018;31(1):e00025-17.

31. Centers for Disease Control and Prevention. Stool specimens-intestinal parasites: comparative morphology tables [Internet]. 2016 [cited 2020 Dec 19]. Available from: https://www.cdc.gov/dpdx/diagnosticprocedures/stool/ morphcomp.html

32. Little MD. Comparative morphology of six species of Strongyloides (Nematoda) and redefinition of the genus. J Parasitol. 1966;52(1):69-84.

33. Booth M, Vounatsou P, N'Goran EK, Tanner M, Utzinger J. The influence of sampling effort and the performance of the Kato-Katz technique in diagnosing Schistosoma mansoni and hookworm co-infections in rural Cote d'Ivoire. Parasitology. 2003;127:525-31.

34. Enk MJ, Lima AC, Drummond SC, Schall VT, Coelho PM. The effect of the number of stool samples on the observed prevalence and the infection intensity with Schistosoma mansoni among a population in an area of low transmission. Acta Trop. 2008:108(2-3):222-8.

35. Knopp S, Salim N, Schindler T, Voules DAK, Rothen J, Lweno O, et al. Diagnostic accuracy of Kato-Katz, FLOTAC, Baermann, and PCR methods for the detection of light-intensity hookworm and Strongyloides stercoralis infections in Tanzania. Am J Trop Med Hyg. 2014;90(3):535-45.

36. Bush AO, Lafferty KD, Lotz JM, Shostak AW. Parasitology meets ecology on its own terms: Margolis et al. revisited. J Parasitol. 1997;83(4):575-83.

37. World Health Organization. Simplified field tables BMI for age Boys 5 to 19 years (z-scores) [Internet]. 2007 [cited 2020 Dec 19]. Available from: https:// www.who.int/growthref/st__bmifa_boys_z_5_19years.pdf?ua=1

38. World Health Organization. Simplified field tables BMI for age Girls 5 to 19 years (z-scores) [Internet]. 2007. [cited 2020 Dec 19]. Available from: https:// www.who.int/growthref/stt_bmifa_girls_z_5_19years.pdf?ua=1.

39. Verweij JJ, Brienen EA, Ziem J, Yelifari L, Polderman AM, Van Lieshout L. Simultaneous detection and quantification of Ancylostoma duodenale, Necator americanus, and Oesophagostomum bifurcum in fecal samples using multiplex real-time PCR. Am J Trop Med Hyg. 2007;77(4):685-90.

40. Knopp S, Mgeni AF, Khamis IS, Steinmann P, Stothard JR, Rollinson D, et al. Diagnosis of Soil-transmitted Helminths in the era of preventive chemotherapy: effect of multiple stool sampling and use of different diagnostic techniques. PLoS Negl Trop Dis. 2008;2(11):0000331.

41. De Alegria M, Colmenares K, Espasa M, Amor A, Lopez I, Nindia A, et al. Prevalence of Strongyloides stercoralis and other intestinal parasite infections in school children in a rural area of Angola: a cross-sectional study. Am J Trop Med Hyg. 2017;97(4):1226-31.

42. Glinz D, N'Guessan NA, Utzinger J, N'Goran EK. High Prevalence of Strongyloides stercoralis Among School Children in Rural Cote d'Ivoire. J Parasitol. 2010;96(2):431-3.

43. Amor A, Rodriguez E, Saugar JM, Arroyo A, López-Quintana B, Abera B, et al. High prevalence of Strongyloides stercoralis in school-aged children in a rural highland of north-western Ethiopia: The role of intensive diagnostic work-up. Parasit Vectors. 2016;9(1):617.

44. Debalke S, Worku A, Jahur N, Mekonnen Z. Soil transmitted helminths and associated factors among schoolchildren in government and private 
primary school in Jimma Town, Southwest Ethiopia. Ethiop J Heal Sci. 2013; 23(3):237-44.

45. Abossie A, Seid M. Assessment of the prevalence of intestinal parasitosis and associated risk factors among primary school children in Chencha town, Southwest Ethiopia. BMC Public Health. 2014;14.

46. Martin J, Keymer A, Isherwood RJ, Wainwright SM. The prevalence and intensity of Ascaris lumbricoides infections in Moslem children from northern Bangladesh. Trans R Soc Trop Med Hyg. 1983;77(5):702-6.

47. Galgamuwa LS, Iddawela D, Dharmaratne SD. Prevalence and intensity of Ascaris lumbricoides infections in relation to undernutrition among children in a tea plantation community, Sri Lanka: a cross-sectional study. BMC Pediatr. 2018;18(1):13.

48. Cooper AJ, Hollingsworth TD. The impact of seasonality on the dynamics and control of Ascaris lumbricoides infections. J Theor Biol. 2018;453:96-107.

49. Mekonnen Z, Getachew M, Bogers J, Vercruysse J, Levecke B. Assessment of seasonality in soil-transmitted helminth infections across 14 schools in Jimma Town, Ethiopia. Pan Afr Med J. 2019;32:6.

50. McGarvey ST, Aligui G, Daniel BL, Peters P, Olveda R, Olds GR. Child growth and schistosomiasis japonica in northeastern Leyte, the Philippines: crosssectional results. Am J Trop Med Hyg. 1992;46(5):571-81.

51. Olds GR, King C, Hewlett J, Olveda R, Wu G, Ouma J, et al. Double-blind placebo-controlled study of concurrent administration of albendazole and praziquantel in schoolchildren with schistosomiasis and geohelminths. J Infect Dis. 1999;179(4):996-1003.

52. Brooker S, Singhasivanon P, Waikagul J, Supavej S, Kojima S, Takeuchi T, et al. Mapping soil-transmitted helminths in Southeast Asia and implications for parasite control. Southeast Asian J Trop Med Public Heal. 2003;34(1):2436.

\section{Publisher's Note}

Springer Nature remains neutral with regard to jurisdictional claims in published maps and institutional affiliations.

Ready to submit your research? Choose BMC and benefit from:

- fast, convenient online submission

- thorough peer review by experienced researchers in your field

- rapid publication on acceptance

- support for research data, including large and complex data types

- gold Open Access which fosters wider collaboration and increased citations

- maximum visibility for your research: over $100 \mathrm{M}$ website views per year

At $\mathrm{BMC}$, research is always in progress.

Learn more biomedcentral.com/submissions 